Article

\title{
Ultrafine Particles in Residential Indoors and Doses Deposited in the Human Respiratory System
}

\author{
Maurizio Manigrasso ${ }^{1, *}$, Ettore Guerriero ${ }^{2, \dagger}$ and Pasquale Avino ${ }^{1, \dagger}$
}

1 Department of Technological Innovations, National Institute for Insurance against Accidents at Work Research Area, via IV Novembre 144, I-00187 Rome, Italy; E-Mail: p.avino@inail.it

2 Institute of Atmospheric Pollution Research, National Research Council, Rome Research Area-Montelibretti, I-00016 Monterotondo Scalo, Italy; E-Mail: guerriero@iiia.cnr.it

$\dagger$ These authors contributed equally to this work.

* Author to whom correspondence should be addressed; E-Mail: m.manigrasso@inail.it; Tel.: +39-06-5487-6418; Fax: +39-06-5487-1.

Academic Editor: Robert Talbot

Received: 29 July 2015 / Accepted: 28 September 2015 / Published: 30 September 2015

\begin{abstract}
Indoor aerosol sources may significantly contribute to the daily dose of particles deposited into the human respiratory system. Therefore, it is important to characterize the aerosols deriving from the operations currently performed in an indoor environment and also to estimate the relevant particle respiratory doses. For this aim, aerosols from indoor combustive and non-combustive sources were characterized in terms of aerosol size distributions, and the relevant deposition doses were estimated as a function of time, particle diameter and deposition site in the respiratory system. Ultrafine particles almost entirely made up the doses estimated. The maximum contribution was due to particles deposited in the alveolar region between the 18 th and the 21 st airway generation. When cooking operations were performed, respiratory doses per unit time were about ten-fold higher than the relevant indoor background dose. Such doses were even higher than those associated with outdoor traffic aerosol.
\end{abstract}

Keywords: aerosol; ultrafine particles; indoors; size distribution; human respiratory system; deposition doses; MPPD 


\section{Introduction}

Many studies have addressed the adverse effects of outdoor particulate pollution on human health. Aerosol pollution in urban environments has been recognized to be responsible for important pathologies of the cardiovascular [1,2] and respiratory systems [3,4]; it has also been associated with increased mortality and hospital admissions [5]. More recently, the International Agency for Research on Cancer (IARC) has considered outdoor pollution as a leading environmental cause of cancer deaths [6-8]. Furthermore, particulate matter, a major component of air pollution, has been classified as carcinogenic to humans (Group 1) [6-8]. Aerosol doses deriving from outdoor sources represent only a part of the daily dose deposited into the human respiratory system. The contribution deriving from indoor sources can be comparatively important considering that people spend more than approximately $80 \%$ of their time indoors $[9,10]$, in confined environments favorable to contaminant accumulation.

Indoor air particle concentration is influenced by the quality of outdoor air and also by the contribution of combustion sources specific to indoor environments. A wide variety of organic compounds have been identified in cooking emissions, including alkanes, alkenes, alkanoic acids, carbonyls and aromatic amines. Most importantly, polycyclic aromatic hydrocarbons (PAHs) [11], heterocyclic amines [12-14] and aldehydes [15-16] are of particular concern in relation to carcinogenicity. Cooking emissions deriving from high-temperature frying have been classified as probably carcinogenic to humans (Group 2A) [17]. Consequently, the contribution of indoor sources may be significant in terms of the number of particles deposited into the respiratory system, as well as in terms of chemical composition and relevant health effects

Within this context, aerosol size distribution measurements represent an important task because the doses deposited in the human respiratory system strictly depend on particle sizes. In this perspective, great attention has been given to ultrafine particles (UFPs, i.e., particles below $100 \mathrm{~nm}$ ) [18-21], because they efficiently penetrate into the respiratory system and are capable of translocating from the airways into the blood circulation [19]. Moreover, knowledge of their distribution in the respiratory tree is important because the airway pathologies caused by the deposition of particulate matter have often been reported to occur at specific sites in the lung [22-24].

For these reasons, the purpose of this work is to study the aerosol concentration and size distribution in a residential indoor environment during a typical day. Such data have been used to estimate the dose of particles deposited in the human respiratory system as a function of time, particle diameter and airway generation number.

\section{Results and Discussion}

\subsection{Aerosol Size Distributions}

Figure la shows the temporal trend of total particle concentration measured in a living room while no operation is occurring. Particle concentration keeps at a quite steady level that can be assumed as the background concentration for the dwelling, until a peak is recorded. The peak concentration is consequent to the window opening for a very short time lapse (about $1 \mathrm{~min}$ ). 
From a background concentration of $1.5 \times 10^{4}$ particles $\mathrm{cm}^{-3}$, the particle concentration is incremented by $67 \%$ at peak concentration $\left(2.5 \times 10^{4}\right.$ particles $\left.\mathrm{cm}^{-3}\right)$ after window opening, with an outdoor concentration of about $3.7 \times 10^{4}$ particles $\mathrm{cm}^{-3}$.

The relevance of outdoor pollution on indoor air quality is addressed by the infiltration factor, defined as the fraction of the outdoor particles that penetrates indoors and remains suspended. Ji and Zhao [25] reviewed the PM10 and PM2.5 infiltration factors reported in the literature for European, North American and Chinese residences. The relevant average values for PM10 were 0.36 for Europe and China and 0.65 for the USA. For PM2.5, they were 0.58 (USA), 0.63 (Europe) and 0.51 (China). While a large fraction of indoor aerosol particles originate from outdoors, many epidemiological studies have examined the association between outdoor particles and mortality [25]. Ji and Zhao [25] point out that a limitation of these studies is that only outdoor PM pollution exposure was measured. They estimated that indoor PM pollution of outdoor origin accounts for $81 \%-89 \%$ of the total increase in mortality associated with exposure to outdoor PM pollution.
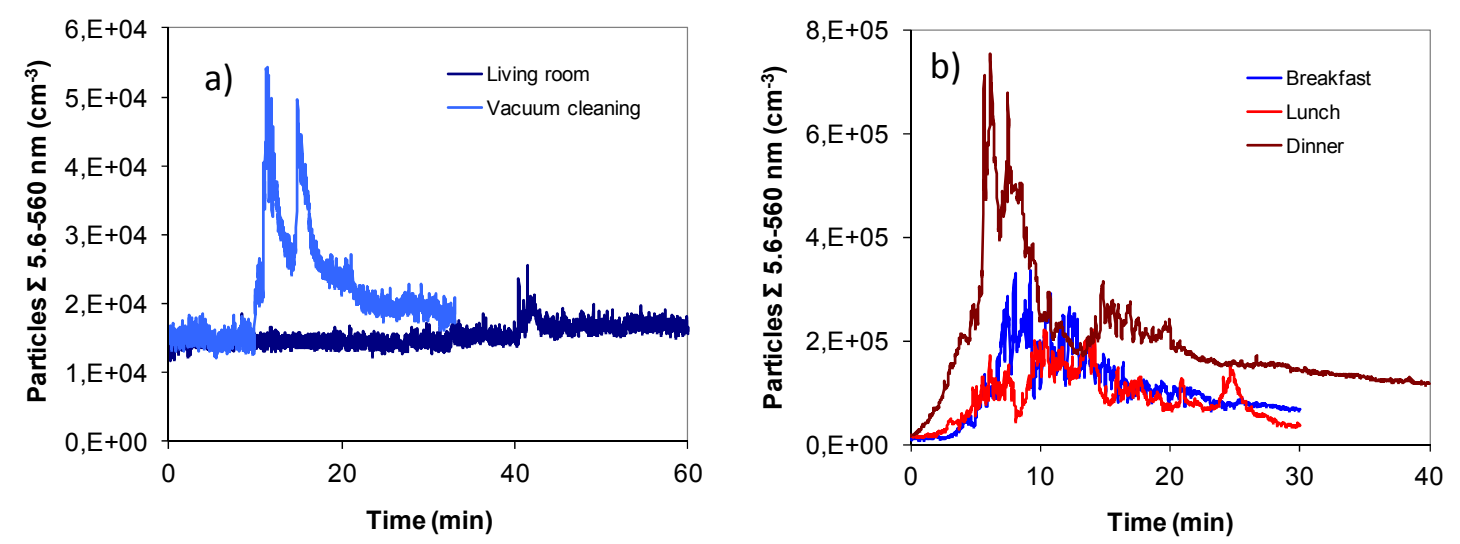

Figure 1. Temporal trends of total $(5.6-560 \mathrm{~nm})$ particle concentration (a) in a living room with no aerosol generation and during vacuum cleaning and (b) in a kitchen during breakfast, lunch and dinner preparation and eating.

The comparison of the two curves in Figure 1a for window opening and vacuum cleaning gives the perception of the importance of indoor aerosol sources with respect to the infiltration of outdoor polluted air. When a vacuum cleaner is set into operation, aerosol is rapidly generated. Within about the same time interval as for window opening, the particle concentration is incremented by $260 \%$ at peak concentration $\left(5.4 \times 10^{4}\right.$ particles $\left.\cdot \mathrm{cm}^{-3}\right)$. Figure $1 \mathrm{~b}$ describes the temporal variation of aerosol concentration measured in the kitchen when a combustion source (methane stove) was in operation at breakfast, lunch and dinner. Maximum particle concentrations were respectively $3.4 \times 10^{5}, 2.2 \times 10^{5}$ and $7.5 \times 10^{5}$ particles. The highest value measured during dinner preparation was due to the higher contribution of the food being cooked to the overall particle concentration: heating milk (breakfast), boiling rice (lunch) compared to meat grilling at dinner.

Figure 2a shows the background particle size distribution together with the aerosol size distributions at the maximum particle concentration value observed in the curves of Figure 1 (window opening and vacuuming). For the background size distributions, a tri-modal curve was observed with modes that in order of importance were at about $80 \mathrm{~nm}, 10 \mathrm{~nm}$ and $19 \mathrm{~nm}$ (almost negligible). The same modes were 
observed for vacuum cleaning, but it is remarkable that the relative importance of the modes was opposite: the mode at $10 \mathrm{~nm}$ increased by 16-fold and was more intense than the one at $80 \mathrm{~nm}$ (almost the same intensity as the background size distribution). Moreover, the mode at $19 \mathrm{~nm}$ was no longer negligible and increased by 34 -fold. Particles settled on the floor are only to a minor extent responsible for such enrichment. The shape of the two concentration peaks in the total particle concentration trend (Figure 1a) suggests that the UFP source operates almost immediately on switching on of the vacuum cleaner. Possibly, it can be originated both from the dust collected in the dust bag and from the emission from the vacuum motor. This finding agrees with other studies [26,27], which showed that vacuuming can be a source of indoor exposure to biological and non-biological aerosols. The authors measured UFP emission rates in the range from $4.0 \times 10^{6}$ to $1.1 \times 10^{11}$ particles $\mathrm{min}^{-1}$. In particular, they pointed out that many vacuum cleaners contain universal motors where carbon brushes can spark with a copper commutator. This is a well-documented technique for generating UFPs with modes in the size distributions at about $10 \mathrm{~nm}$ or below [28]. According to this finding Knibbs et al. [26] and Veillette et al. [27] measured count median diameter (CMD) as low as $15 \mathrm{~nm}$ : they concluded that particle emission from the motors of vacuum cleaners is very likely the dominant UFP production mechanism. For such reasons, very likely, the mode at $10 \mathrm{~nm}$ in the size distribution for vacuum cleaning in Figure 2a is due to particle emission from the vacuum motor.
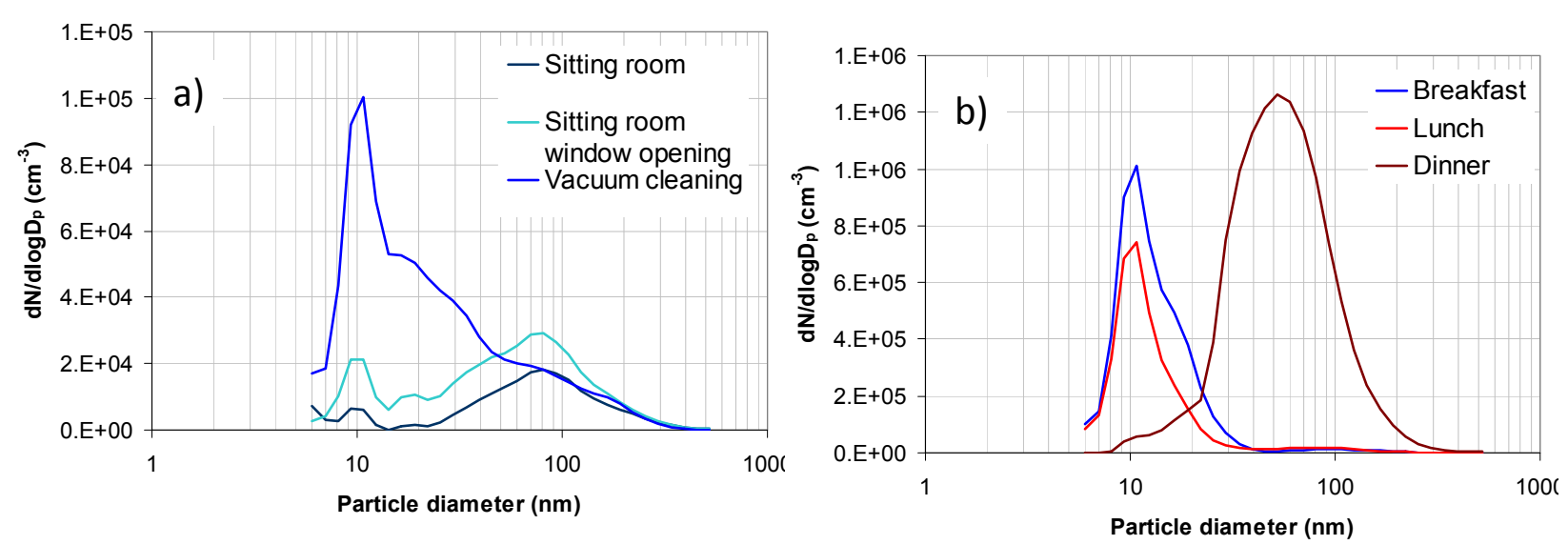

Figure 2. Aerosol size distribution at the maximum particle concentration value (a) in a living room with no aerosol generation and during vacuum cleaning and (b) in a kitchen during breakfast, lunch and dinner preparation and eating.

All of the aerosol size distributions in Figure $2 \mathrm{~b}$ refer to cooking operations, but their modes markedly differ: about $10 \mathrm{~nm}$ for breakfast and lunch and about 50 for dinner. Aerosol size distributions measured for breakfast and lunch preparations are very similar to those measured by other authors [29] for domestic gas cooker burning methane with the mode at about $10 \mathrm{~nm}$, suggesting a negligible contribution from food (i.e., milk heating and rice boiling). As expected, for such measurements, the main contribution was due to methane burning, because of the negligible emissions deriving from the food. On the contrary, during dinner preparation (meat grilling), the main contribution to particle emission arose from the food. The relevant aerosol size distribution is in fact in agreement with those reported in the literature [30] for grilling of fatty foods with modes ranging between 40 and $50 \mathrm{~nm}$. Particle concentrations as high as $7.5 \times 10^{5} \mathrm{~cm}^{-3}$ have been measured (Figure 1b). Such values are in the range of 
those reported in the literature for different kinds of cooking activities varying from $3.5 \times 10^{4} \mathrm{~cm}^{-3}$ to $5.6 \times 10^{6} \mathrm{~cm}^{-3}$ [31-39]. Such variability is due to the different types of cooking, as well as to the different geometry and ventilation where the measurements were performed.

Moreover, Wallace et al. [40] made measurements of size distributions on cooking emissions in the 2-64-nm size range and found that peak concentrations from the gas and the electric stovetop burners/coil occurred at particle sizes of about $5 \mathrm{~nm}$. They found total concentrations as much as 10-times greater than reported in other studies of particle sizes above $10 \mathrm{~nm}$. In this study, particle size measurements were performed above $5.6 \mathrm{~nm}$; therefore, the total concentrations and then the relevant doses calculated may be to some extent underestimated.

As reported by other authors [33,41], more than $90 \%$ of the particle concentration deriving from cooking activities is made up of UFPs. Figures $3 \mathrm{a}$ and $3 \mathrm{~b}$ show the concentrations as a function of time of 9 and 52-nm sized particles, respectively, for milk heating and meat grilling. These are the modes of the aerosol size distribution for milk heating and for meat grilling, respectively (Figure 2b). Figures $3 \mathrm{c}$ and $3 \mathrm{~d}$ show the relevant temporal trend of variation of UFP $\%$ contribution.

The highly time-resolved aerosol measurements (1-s time resolution) allowed following the different dynamics of UFP generation of the two cooking activities. During milk heating, the 52-nm particle concentration remained quite constant (no emission from food), whereas the 9-nm particle concentration steadily increased (Figure 3a) and so did the UFP \% contribution, which reached values above 95\% (Figure 3c). For meat grilling (Figure 3b), the 9-nm particle concentration steeply increased (methane combustion), went through a maximum and dropped. The 9-nm data points followed a decreasing trend and started being extremely scattered when the concentration of 52-nm particles (from meat) steeply increased.

The decrease of the 9-nm particle concentration after the peak value may be attributable to a combination of several mechanisms, like coagulation, ventilation and diffusional deposition, which are interconnected. On this point, Rim et al. [42] developed a particle dynamics model that predicts the temporal changes of the aerosol size distribution following an episodic release of high concentration UFPs. The authors focused on the decay period after particle emission from different sources. Model estimates were compared to scanning mobility particle sizer (SMPS) measurements (2.5-min time resolution). For aerosol emitted by a gas stove, the particle peak occurred between $4 \mathrm{~nm}$ and $10 \mathrm{~nm}$. In the SMPS scans following the beginning of the decay period, the particle size distributions shifted over time toward larger diameters. The authors showed that this shift was mainly due to the coagulation effect. The coagulation effect seemed to be greater for small particles than for larger particles. The fast disappearance of small particles occurred because of higher concentrations and the higher mobility of small particles than larger particles.

The measurements described in Figure $3 b$ were carried out during the aerosol generation when strong aerosol emissions derived both from methane combustion and from meat grilling. Therefore, in this case, the coagulation mechanism was even more important because particles greater than $100 \mathrm{~nm}$ were generated (Figure 2b), and the probability of the collision of small particles (e.g., $9 \mathrm{~nm}$ in Figure $3 b$ ) on larger ones (e.g., $52 \mathrm{~nm}$ in Figure 3b) is higher than on small ones (i.e., when particles are only derived from methane combustion), due to the greater cross-section. 
As a consequence, the temporal trend of UFP \% (Figure 3d) displays a maximum. Moreover, such a maximum is also due to the broader size distribution of aerosol from meat grilling that includes particles greater than $100 \mathrm{~nm}$ (Figure $2 \mathrm{~b}$ ).
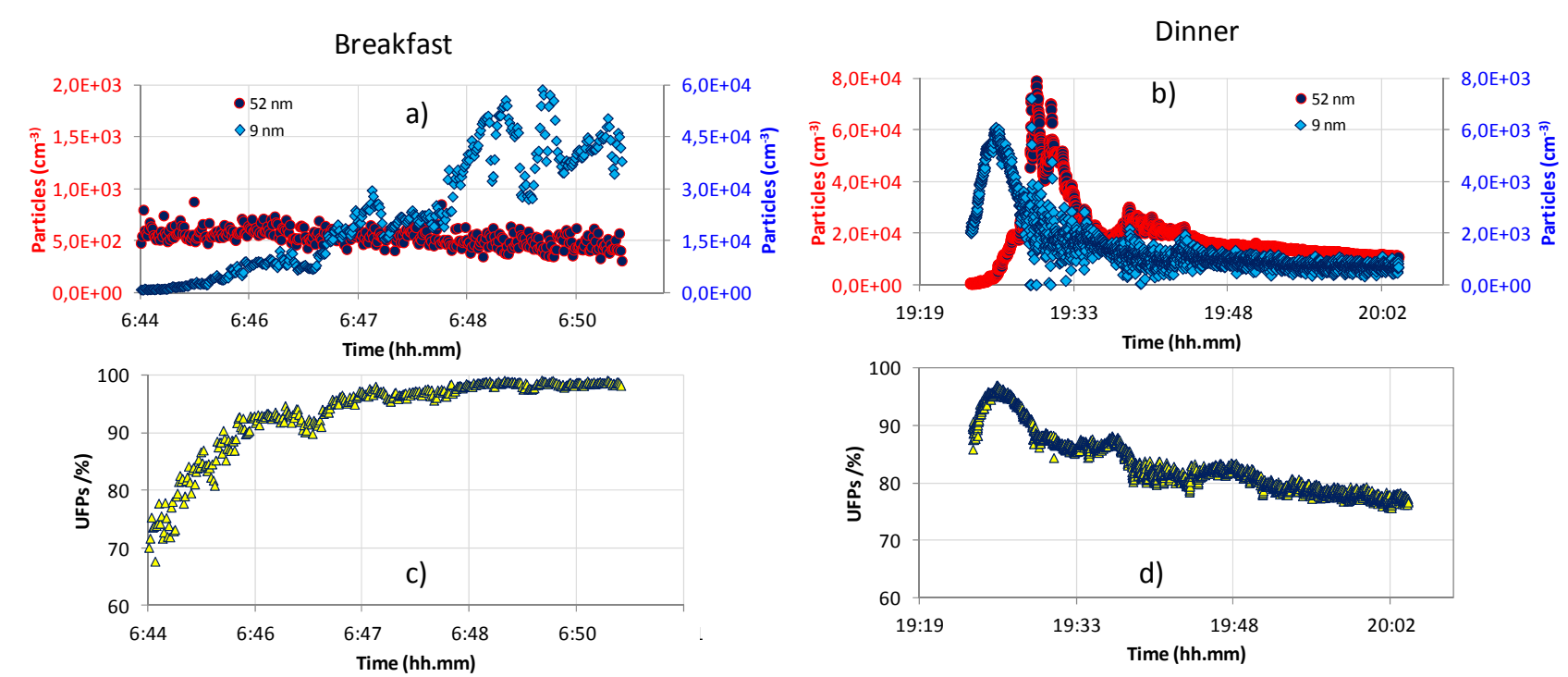

Figure 3. Temporal trends of 9-nm and 52-nm sized particles for (a) breakfast (milk heating) and (b) dinner (meat grilling) preparation and of the ultrafine particle (UFP) \% contribution to total particle concentration $(5.6-560 \mathrm{~nm})$ for $(\mathbf{c})$ breakfast and (d) dinner preparation.

\subsection{Dosimetry Estimates}

The structure of the human airway system can be described as a sequence of dichotomous branching that starts from the trachea. The progressively bifurcating airways are classified by their generation number; the trachea is identified as Generation 1 [43].

Dosimetry estimates are reported as a function of time, particle size and airway generation number. In Figures 4-8, dosimetry estimates are shown respectively for a living room (no generation activity), vacuum cleaning, breakfast, lunch and dinner preparation. Each figure is made up of three plots: (a) $D_{T}(t)$ as a function of time; (b) $D_{G}(t, G)$ as a function of time and of airway generation number; and (c) $D\left(d, t_{\text {Max }}, G\right)$ as a function of particle diameter and of airway generation number, where $t_{\text {Max }}$ is the time when $D_{T}(t)$ is maximum (the red cross in Plot a).

All contour plots of $D\left(d, t_{\text {Max }}, G\right)$ as a function of particle diameter and of airway generation number display a well-defined single-peak value $\left(D\left(d_{\operatorname{Max}}, t_{\operatorname{Max}}, G_{\operatorname{Max}}\right)\right)$, with the exception of Figure $4 \mathrm{c}$, where a two-peak profile is displayed. Such a difference is due to the two main modes at 10 and $80 \mathrm{~nm}$, measured in the particle size distributions when no indoor generation event was occurring (Figure 2a).

When combustion sources were active, the mode at $80 \mathrm{~nm}$ became negligible as in the case of breakfast and lunch preparation (mainly emission from methane combustion) or hidden below the broader size distribution deriving from meat grilling.

Table 1 summarizes the cumulative doses $D_{c}\left(t_{R}\right)$, the cumulative doses per unit time $D_{c}\left(t_{R}\right) / t_{R}$ at the end of the residence time $\left(t_{R}\right)$ in each indoor environment, the maximum value of the total instant dose 
$D_{T}\left(t_{\text {Max }}\right)$, the maximum value of the instant doses $D(d, t, G)$ at $t_{\text {Max }}$ and the relevant value of $d\left(d_{\text {Max }}\right)$ and airway generation number $G\left(G_{M a x}\right)$.

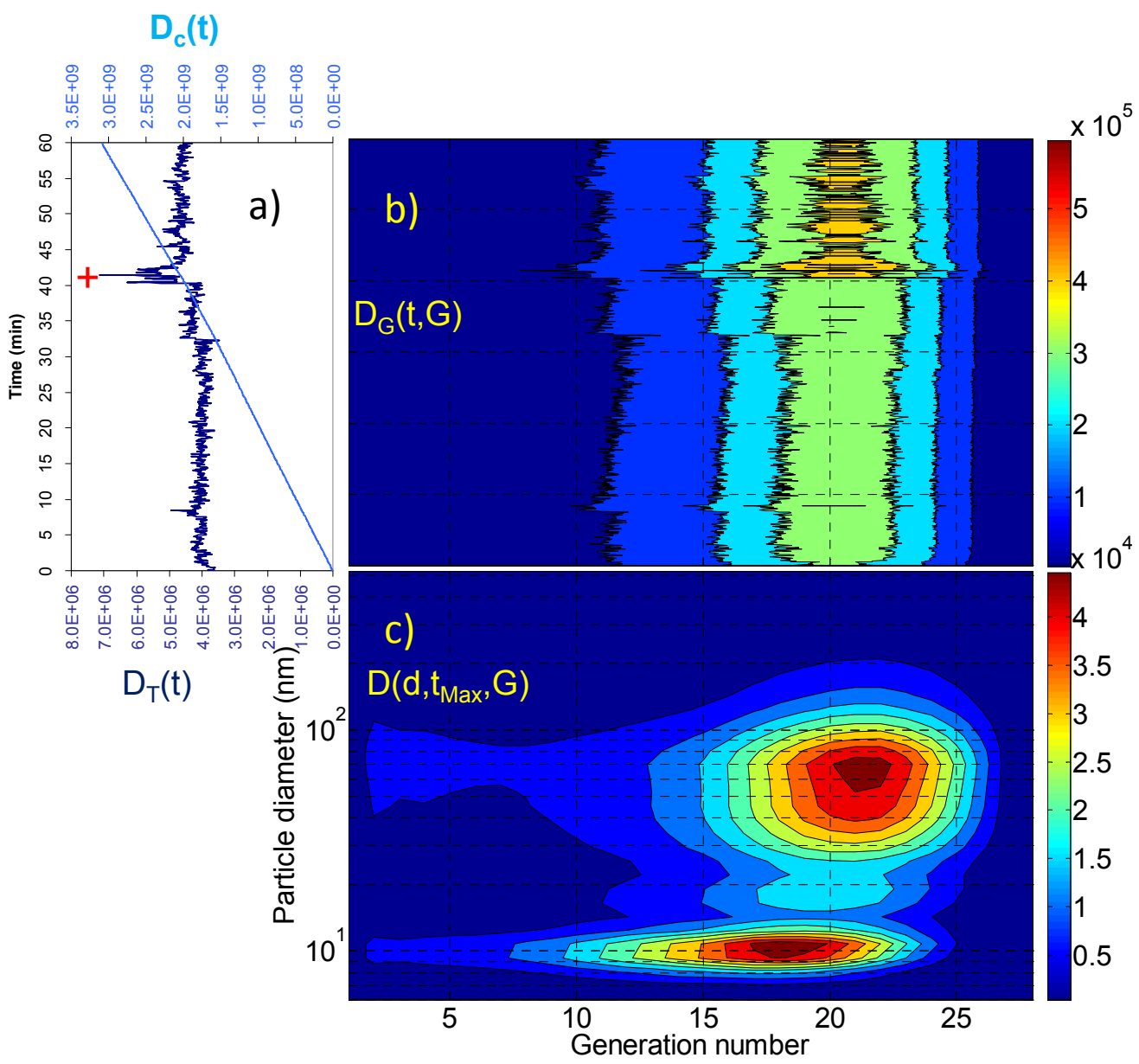

Figure 4. Living room: (a) total instant dose $D_{T}(t)$ and cumulative dose $D_{c}(t)$ as a function of time; (b) instant dose per airway generation $D_{G}(t, G)$ as a function of time and airway generation number; (c) maximum instant dose $D\left(d, t_{M a x}, G\right)$ at the maximum $D_{T}(t)$ value (the red cross in (a)) as a function of particle diameter and of airway generation number.

Table 1. Cumulative doses $D_{c}\left(t_{R}\right)$, cumulative doses per unit time $D_{c}\left(t_{R}\right) / t_{R}$ at the end of the residence time $\left(t_{R}\right)$, maximum value of the total instant dose $\mathrm{D}_{\mathrm{T}}\left(\mathrm{t}_{\mathrm{Max}}\right)$, maximum value of the instant doses $D(d, t, G)$ at $t_{\text {Max }}$ and relevant value of $d\left(d_{M a x}\right)$ and airway generation number $G$ $\left(G_{M a x}\right)$ in a living room and a kitchen (breakfast, lunch and dinner).

\begin{tabular}{|c|c|c|c|c|c|c|}
\hline & $\begin{array}{c}D_{c}\left(t_{R}\right) \\
\text { (particles) }\end{array}$ & $\begin{array}{c}D_{c}\left(t_{R}\right) / t_{R} \\
\left(\text { particles } \times \min ^{-1}\right)\end{array}$ & $\begin{array}{c}D_{T}\left(t_{M a x}\right) \\
\text { (particles) }\end{array}$ & $\begin{array}{c}D\left(d_{M a x}, t_{M a x}, G_{M a x}\right) \\
\text { (particles) }\end{array}$ & $\boldsymbol{G}_{M a x}$ & $\begin{array}{l}d_{\text {Max }} \\
(\mathrm{nm})\end{array}$ \\
\hline \multirow{2}{*}{ Living room } & \multirow{2}{*}{$3.09 \times 10^{9}$} & \multirow{2}{*}{$5.15 \times 10^{7}$} & \multirow{2}{*}{$7.12 \times 10^{6}$} & $4.83 \times 10^{4}$ & 18 & 10.8 \\
\hline & & & & $4.73 \times 10^{4}$ & 21 & 69.8 \\
\hline Vacuuming & $2.85 \times 10^{9}$ & $8.64 \times 10^{7}$ & $2.01 \times 10^{7}$ & $2.33 \times 10^{5}$ & 18 & 10.8 \\
\hline Breakfast & $1.59 \times 10^{10}$ & $5.30 \times 10^{8}$ & $1.26 \times 10^{8}$ & $2.32 \times 10^{6}$ & 18 & 10.8 \\
\hline Lunch & $1.31 \times 10^{10}$ & $4.37 \times 10^{8}$ & $8.86 \times 10^{7}$ & $1.67 \times 10^{6}$ & 18 & 10.8 \\
\hline Dinner & $2.78 \times 10^{10}$ & $6.95 \times 10^{8}$ & $2.15 \times 10^{8}$ & $2.33 \times 10^{6}$ & 21 & 45.3 \\
\hline
\end{tabular}




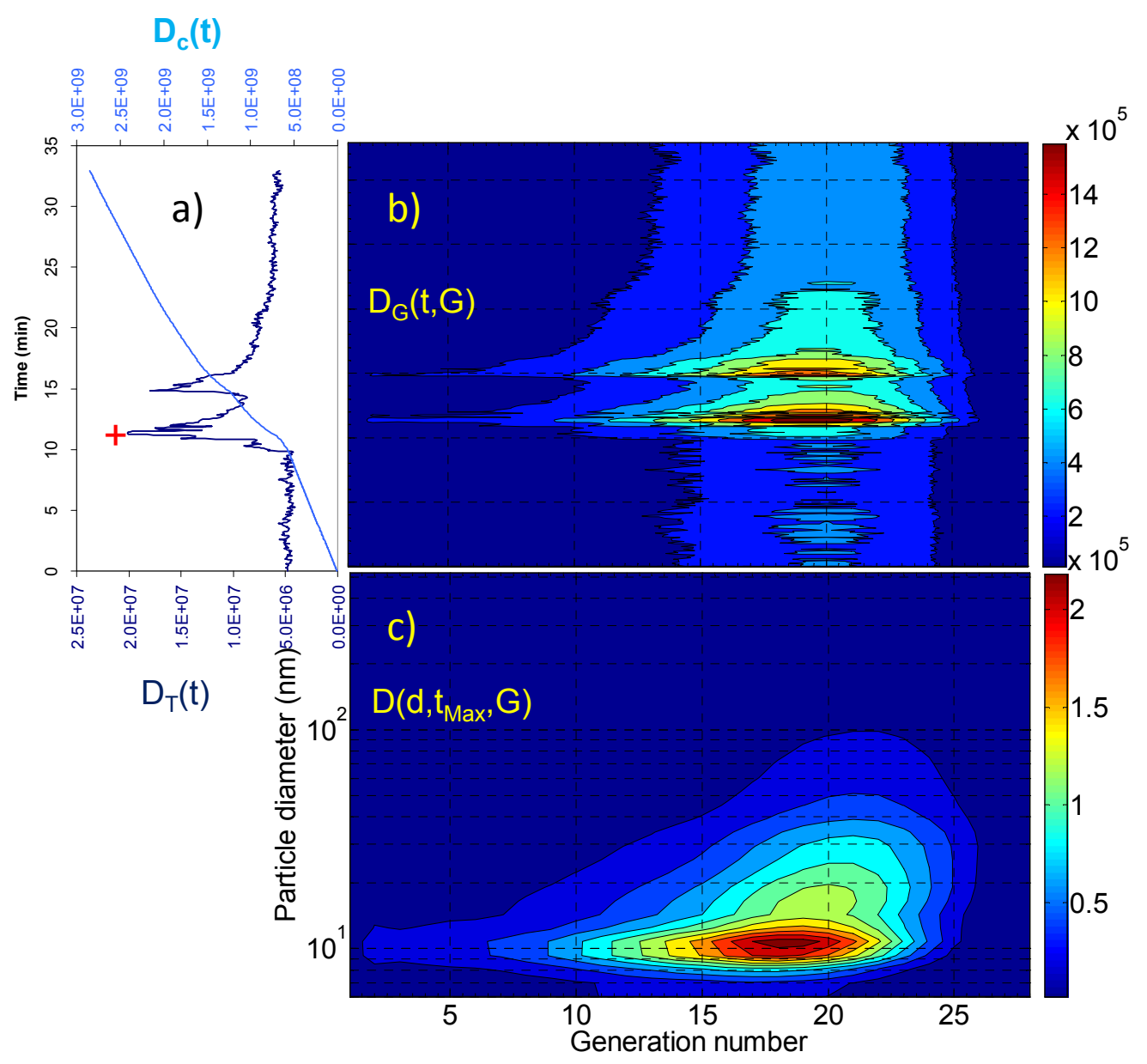

Figure 5. Living room, vacuum cleaning: (a) total instant dose $D_{T}(t)$ and cumulative dose $D_{c}(t)$ as a function of time; (b) instant dose per airway generation $D_{G}(t, G)$ as a function of time and airway generation number; (c) maximum instant dose $D\left(d, t_{M a x}, G\right)$ at the maximum $D_{T}(t)$ value (the red cross in (a)) as a function of particle diameter and of airway generation number.

The highest value of $D_{c}\left(t_{R}\right)$ was estimated for dinner cooking $\left(2.78 \times 10^{10}\right.$ particles $)$ and the lowest for vacuum cleaning $\left(2.85 \times 10^{9}\right.$ particles). It should be noted that each environment was resided in for different times $\left(t_{R}\right)$, in particular the living room was resided in for $60 \mathrm{~min}$ and $33 \mathrm{~min}$, respectively, in the absence of aerosol generation and during vacuum cleaning. Therefore, if the relevant $D_{c}\left(t_{R}\right)$ values are normalized, dividing by $t_{R}$, the doses per unit time are respectively equal to $5.15 \times 10^{7}$ and $8.64 \times 10^{7}$ particles $\times \mathrm{min}^{-1}$, i.e., higher for vacuuming than for simply residing in the living room. Accordingly, $D_{T}\left(t_{\operatorname{Max}}\right)$ and $D\left(d_{\operatorname{Max}}, t_{\operatorname{Max}}, G_{\operatorname{Max}}\right)$ were higher for vacuuming (respectively $2.01 \times 10^{7}$ and $2.33 \times 10^{5}$ particles) than in the absence of generation events (respectively $7.12 \times 10^{6}$ and $4.83 \times 10^{4}$ particles). Moreover, it is worth observing that in the absence of indoor emission sources with particle concentrations of about $1.5 \times 10^{4}$ and $3.7 \times 10^{4}$ particles $\mathrm{cm}^{-3}$, respectively indoors and outdoors, keeping the window opened (for about $1 \mathrm{~min}$ ) determined an increment of the instant dose $D_{T}(t)$ as high as about $70 \%$ (Figure $4 a)$. 


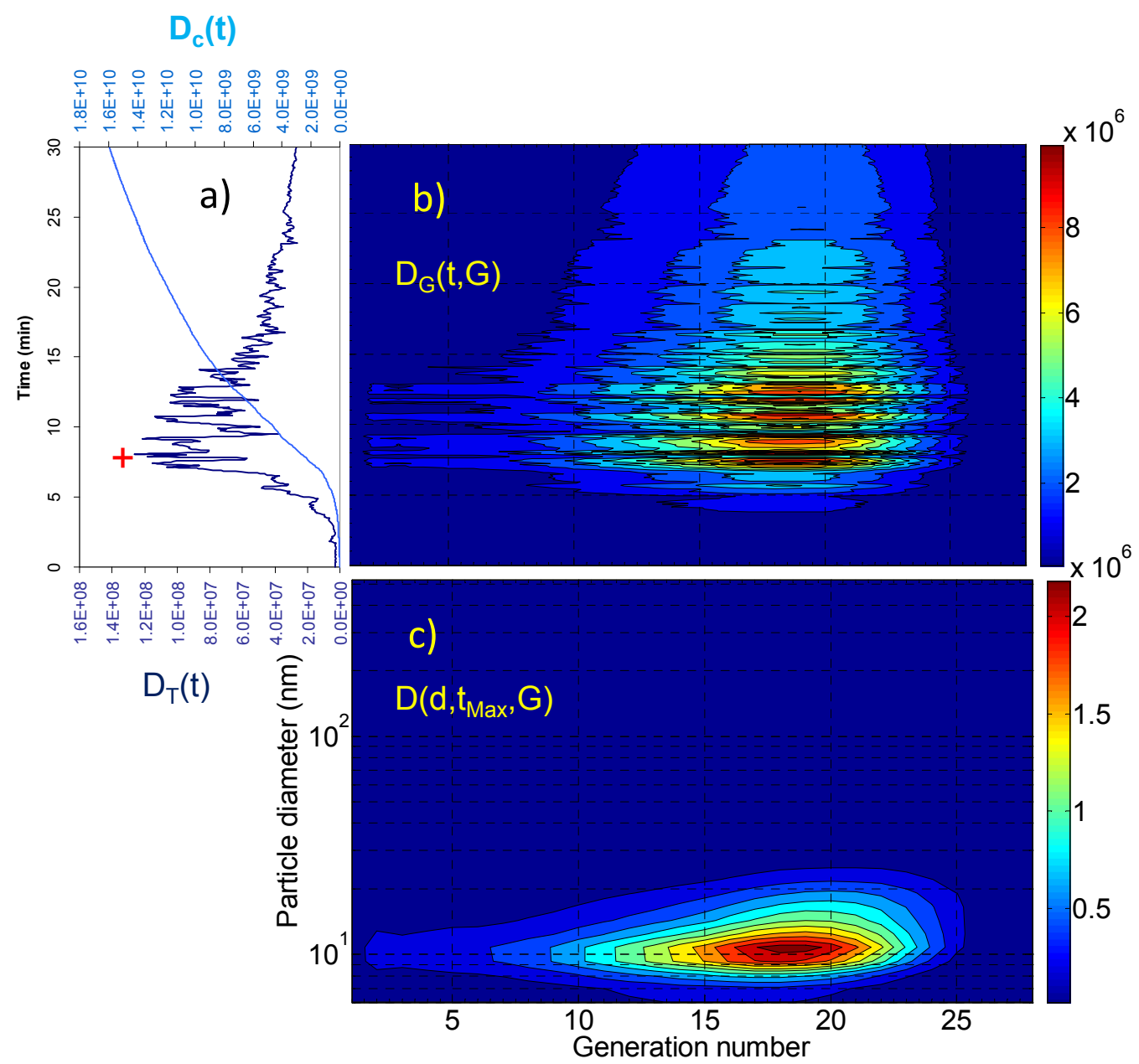

Figure 6. Kitchen, breakfast preparation and eating: (a) total instant dose $D_{T}(t)$ and cumulative dose $D_{c}(t)$ as a function of time; (b) instant dose per airway generation $D_{G}(t, G)$ as a function of time and airway generation number; (c) maximum instant dose $D\left(d, t_{\text {Max }}, G\right)$ at the maximum $D_{T}(t)$ value (the red cross in (a)) as a function of particle diameter and of airway generation number.

When combustion sources are active (Figures 6-8), cumulative doses per unit time $\left(D_{c}\left(t_{R}\right) / t_{R}\right)$ were about ten-fold higher than the background dose $\left(5.15 \times 10^{7}\right.$ particles $\left.\times \mathrm{min}^{-1}\right)$. The highest value was estimated for meat grilling $\left(6.95 \times 10^{8}\right.$ particles $\left.\times \mathrm{min}^{-1}\right)$. Instant dose size distributions $D\left(d, t_{\text {Max }}, G\right)$ as a function of particle diameter and airway generation number (Figures $6 \mathrm{c}-8 \mathrm{c}$ ) show that particle doses were almost entirely made up of UFPs. The maximum instant doses $D\left(d_{\operatorname{Max}}, t_{\text {Max }}, G_{\operatorname{Max}}\right)$ were deposited in the alveolar region at the 18th airway generation for 10-nm particles (Figures 6c-7c), with the exception of dinner preparation (meat grilling). Due to the markedly different aerosol size distribution (Figure 2b), the greater contribution was due to the $45-\mathrm{nm}$ particles deposited at the 21 st airway generation (Figure 8c). 


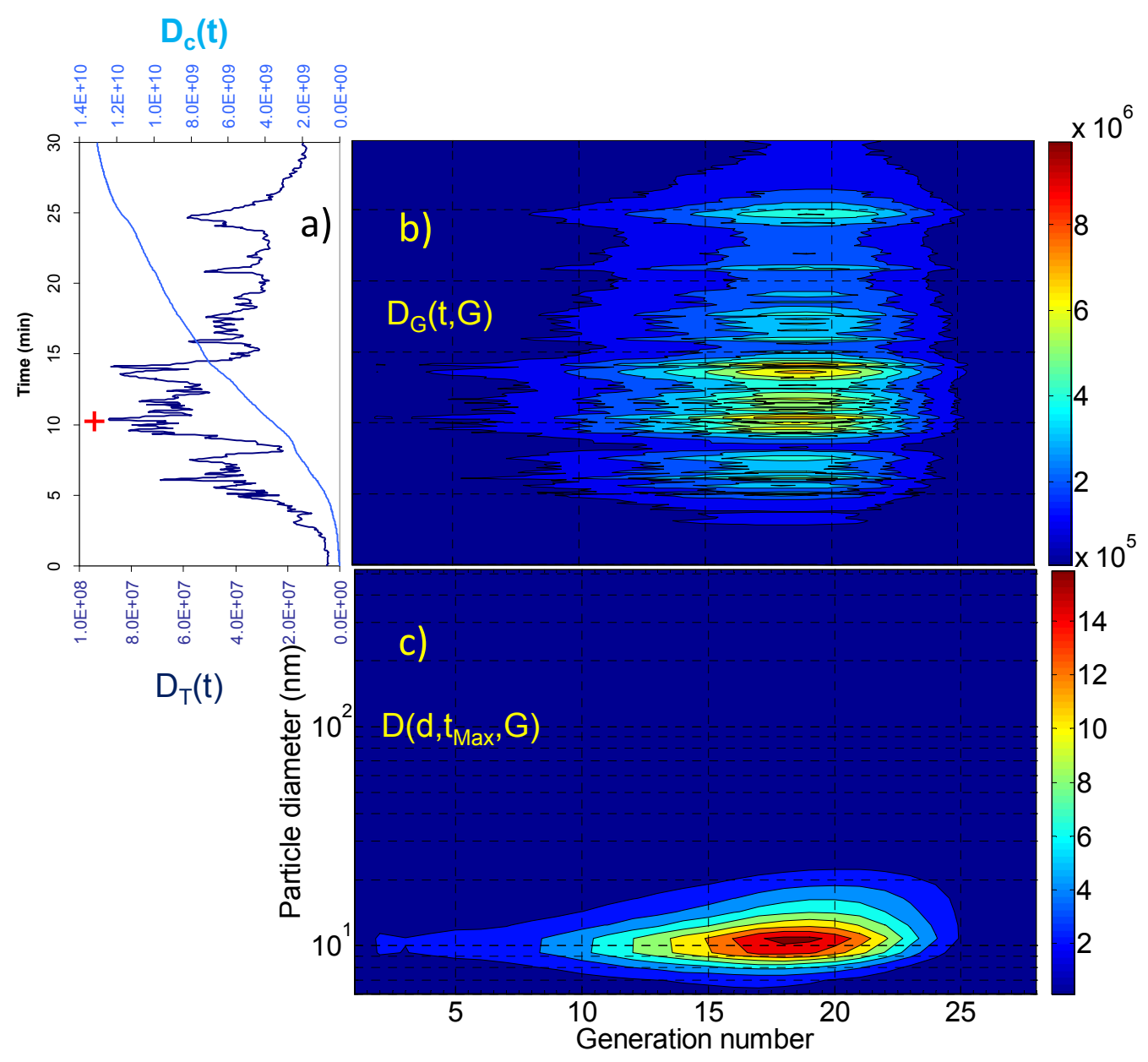

Figure 7. Kitchen, lunch preparation and eating: (a) total instant dose $D_{T}(t)$ and cumulative dose $D_{c}(t)$ as a function of time; (b) instant dose per airway generation $D_{G}(t, G)$ as a function of time and airway generation number; (c) maximum instant dose $D\left(d, t_{\text {Max }}, G\right)$ at the maximum $D_{T}(t)$ value (the red cross in (a)) as a function of particle diameter and of airway generation number.

To estimate the relative importance of aerosol doses deriving from indoor environments with respect to outdoor environments, a comparison has been made with the particle doses due to traffic aerosol. As a reference, after one hour of exposure in downtown Rome in a street with traffic, $2.30 \times 10^{10}$ particles are deposited in the tracheobronchial and alveolar regions [44]. The ratio of the cumulative doses per unit time $D_{c}\left(t_{R}\right) / t_{R}$ estimated for indoor environments to the dose per unit time due to traffic aerosol $\left(3.83 \times 10^{8}\right.$ UFPs $\left.\times \min ^{-1}\right)$ is 0.13 (living room) and 0.23 (vacuuming) when no combustion source is active. When combustion sources are in operation, such a ratio becomes greater than one, i.e., 1.38, 1.14 and 1.81, respectively, for breakfast, lunch and dinner preparation.

Buonanno et al. [45] combined the average particle size distribution for different outdoor and indoor Italian microenvironments, with activity pattern data. By means of a Monte Carlo methodology, they estimated the tracheobronchial and alveolar dose of submicrometer particles for different population age groups in Italy. The daily particle number deposited for all of the age groups considered was equal to $1.5 \times 10^{11}$ and $6.5 \times 10^{10}$ particles, respectively, for the alveolar and the tracheobronchial regions. The percent contribution of the cumulative doses $D_{c}\left(t_{R}\right)$ estimated in this work when indoor aerosol 
generation events occurred (Table 1) ranges from 1.3\% for vacuuming to $12.9 \%$ for dinner (meat grilling). Considering the summation of the relevant $D_{c}\left(t_{R}\right)$ values (Table 1), their contribution to the total daily dose $\left(2.15 \times 10^{11}\right.$ particles, i.e., the sum of alveolar and tracheobronchial doses $)$ estimated by Buonanno et al. [45], was $27.7 \%$.

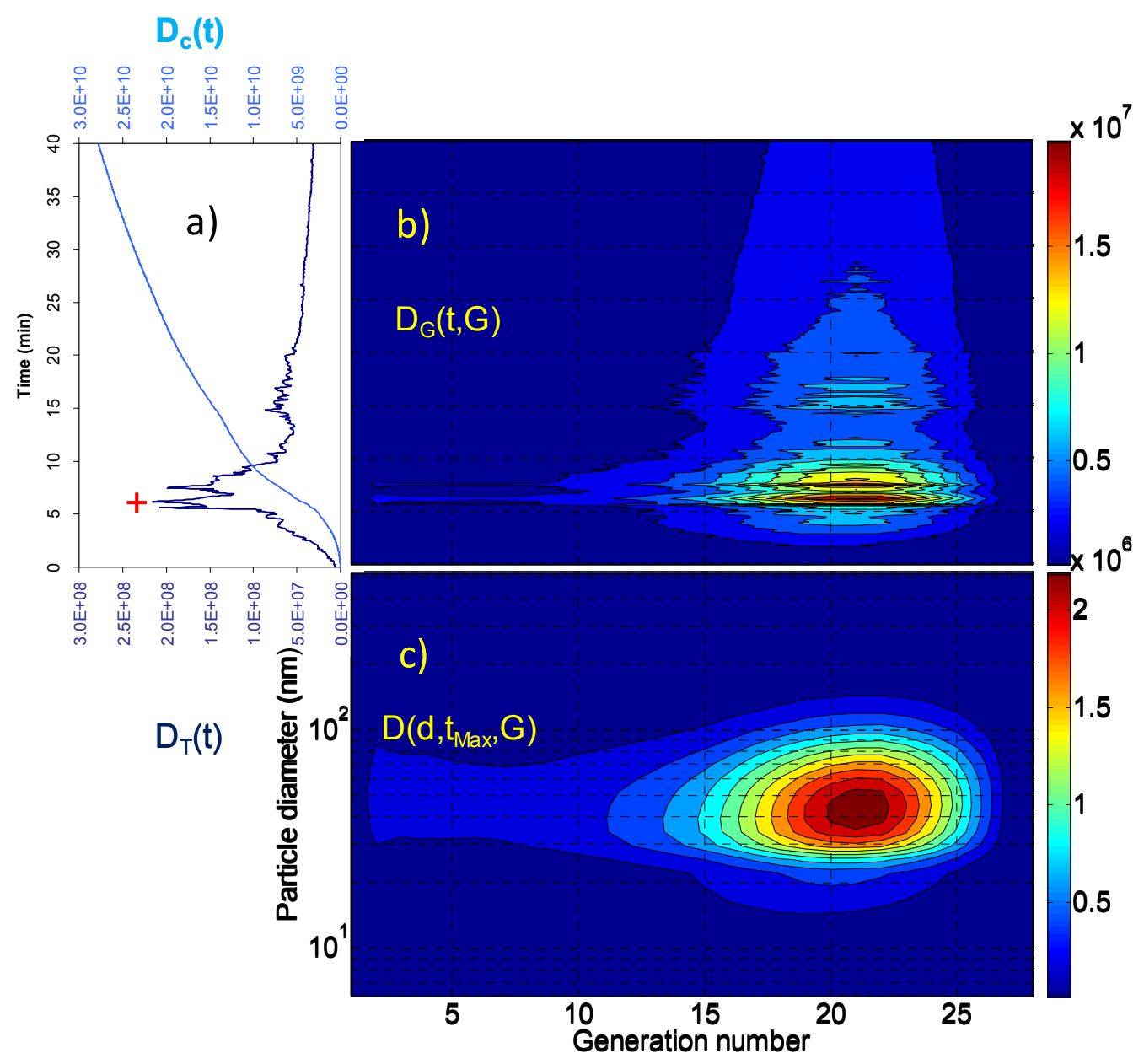

Figure 8. Kitchen, dinner preparation and eating room: (a) total instant dose $D_{T}(t)$ and cumulative dose $D_{c}(t)$ as a function of time; (b) instant dose per airway generation $D_{G}(t, G)$ as a function of time and airway generation number; (c) maximum instant dose $D\left(d, t_{\text {Max }}, G\right)$ at the maximum $D_{T}(t)$ value (the red cross in (a)) as a function of particle diameter and of airway generation number.

The health relevance of such estimates can be addressed by the risk assessment of indoor aerosol reported by Morawska et al. [46]. They pointed out that the burden of disease from indoor-generated particles could reach the order of $1-3 \times 10^{3}$ healthy life years lost per million inhabitants in developed countries every year.

Finally, it should be considered that this study is based on measurements performed in one residence, both in a living room and a kitchen. Aerosol concentrations and size distributions change in relation to the dwelling geographical (less or more polluted areas) and urban (near or far from high traffic areas) location, indoor volume and surface area, ventilation, occupancy pattern, indoor sources (e.g., presence of tobacco and/or electronic cigarette smokers, different cooking preparations, usage of electric 
appliances, candle burning, presence of fire places, usage of air freshener sprays, usage of laser printers and/or photocopiers) and the formation of particles through the reactions of gas-phase precursors. Such changes are reflected in the variations of the aerosol doses and of their distribution into the respiratory system.

\section{Experimental Section}

\subsection{Aerosol Measurements}

Aerosol size distributions were measured by means of a TSI Fast Mobility Particle Sizer (Model 3091, FMPS, Shoreview, MN, USA). The instrument counts and classifies particles, according to their electrical mobility, in 32 size channels, in the range from 5.6 to $560 \mathrm{~nm}$, with a 1-s time resolution. FMPS operates at a high flow rate $\left(10 \mathrm{~L} \cdot \mathrm{min}^{-1}\right)$ to minimize UFP diffusion losses. It operates at ambient pressure to prevent evaporation of volatile and semivolatile particles [47-49]. The performance of the FMPS was investigated by comparison with a scanning mobility particle sizer (SMPS) [50]. The authors evaluated that the SMPS concentration, in the size range from $6 \mathrm{~nm}$ to $100 \mathrm{~nm}$, is about $34 \%$ lower than the FMPS measurements, due to the diffusion losses of particles in the SMPS. The diffusion loss-corrected SMPS concentration is on average about 15\% higher than the FMPS data.

In this study, measurements were performed in the living room and the kitchen where people spend a great part of the day. In the living room, measurements were carried out when no aerosol-generating activity was being performed and during vacuum cleaning. In the kitchen, aerosol measurements were performed at breakfast, lunch and dinner when milk heating, rice boiling and meat grilling were respectively performed using a gas stove. The windows were opened after each measurement for 20-30 min, allowing a rebalancing of the room atmosphere.

The air exchange rate $(\lambda)$ was calculated by the tracer gas technique. $\mathrm{CO}_{2}$ was used as a tracer gas. It was released from a cylinder into the ambient air until a relatively stable concentration was reached; then, the decaying $\mathrm{CO}_{2}$ concentration was measured over time by using the concentration decay function [51]:

$$
\ln C(t)=\ln C_{0}-\lambda t
$$

where $\lambda$ equal to $0.8 \mathrm{~h}^{-1}$ was calculated via linear regression analysis.

\subsection{Particle Dose Evaluation}

Particle deposition in the human respiratory system was evaluated using the multiple-path particle dosimetry model (MPPD v2.1, ARA 2009), which calculates the deposition and clearance of mono- and poly-disperse aerosols, from ultrafine to coarse particles, in the respiratory system of humans and rats [52-56]. The model includes single and multiple path methods to calculate airflow and aerosol deposition. Dosimetry estimates were made by means of the stochastic lung model, because it provides a more realistic lung geometry than the symmetric one considered in the International Commission on Radiological Protection (ICRP) model [57]. In the MPPD model, the ten stochastic lungs are ordered in size (total number of airways) from the smallest to the largest, and the approximate size percentile of each lung is provided [58]. The 60th percentile human stochastic lung was considered in this study. The 
following settings were considered in the application of the MPPD model: (i) a uniformly-expanding flow; (ii) an upright body orientation; and (iii) nasal breathing with a 0.5 inspiratory fraction and no pause fraction. Moreover, the following parameters were used for a Caucasian adult male under the sitting-awake condition, based on the ICRP report [58]: (i) a functional residual capacity (FRC) of $3300 \mathrm{~mL}$; (ii) an upper respiratory tract (URT) volume equal to $50 \mathrm{~mL}$; (iii) a 12- $\mathrm{min}^{-1}$ breathing frequency; and (iv) an air volume inhaled during a single breath (tidal volume, $V_{T}$ ) of $0.75 \mathrm{~L}$.

Particle deposition doses as a function of time $(t)$, particle diameter $(d)$ and generation number $(G)$, under the hypothesis of spherical particles, were calculated as follows:

(i) instant doses $D(d, t, G)$ :

$$
D(d, t, G)=C(d, t) \times F(d, G) \times V_{T}
$$

where $F(d, G)$ is the deposition fraction at a given airway generation and particle diameter and $C(d, t)$ is the concentration of particles of diameter $d$ at a given time $t$ averaged over a single respiratory act time interval;

(ii) instant dose per airway generation $D_{G}(t, G)$ :

$$
D_{G}(t, G)=\sum_{d=d 1}^{d=d 32} D(d, t, G)
$$

The summation in Equation 3 is carried out over the 32 FMPS size classes;

(iii) total instant doses $D_{T}(t)$ :

$$
D_{T}(t)=\sum_{G=1}^{28} D_{G}(t, G)
$$

The summation in Equation 4 is carried out over the 28 airway generations;

(iv) cumulative doses deposited at the end of a given residence time $\left(t_{R}\right)$ in each indoor environment $D_{c}\left(t_{R}\right)$ :

$$
D_{c}\left(t_{R}\right)=\sum_{t=0}^{t_{R}} D_{T}(t)
$$

where $t_{R}$ was 60, 33, 30, 30 and $40 \mathrm{~min}$, respectively, for living room residence (no aerosol generation), living room during vacuum cleaning, breakfast, lunch and dinner preparation and eating.

\section{Conclusions}

Indoor activities considered in this work (vacuuming, breakfast, lunch and dinner preparation) generate aerosols that cause significant increments of the particle concentrations above the indoor background levels, even at concentrations greater than those measured in outdoor environments.

Overall, the indoor activities considered represent a relevant contribution $(27 \%)$ to the total daily dose. The cumulative doses estimated vary from $2.85 \times 10^{9}$ particles for vacuuming to about ten-fold higher for meat grilling. Indoor cooking is one of the most important sources, because it generates aerosol at a high concentration and within a relatively short time span.

Depending on the aerosol source, the UFP \% contribution to indoor aerosol increased from $70 \%$ to $80 \%$ of the background values up to above $95 \%$. Coherently, the aerosol dose deposited in the respiratory system is mainly due to UFPs, with peak values in the alveolar regions between the 18 th and the 21 st 
airway generation. Considering the relevant impact on human health of indoor aerosols, epidemiological studies based on outdoor data should be integrated with investigations linking indoor aerosol concentrations to health endpoints.

\section{Acknowledgments}

The authors wish to thank ARA for MPPD Version 2.1.

This study was supported by National Institute for Insurance against Accidents at Work (INAIL) Grants P20L09 and P20L01.

\section{Author Contributions}

Maurizio Manigrasso and Pasquale Avino were responsible for the research design. Pasquale Avino and Ettore Guerriero conducted the field work. Maurizio Manigrasso performed the computational work. The paper was written by Maurizio Manigrasso with contributions by Pasquale Avino. All of the authors approved the paper.

\section{Conflicts of Interest}

The authors declare no conflict of interest.

\section{References}

1. Brook, R.D.; Brook, J.R.; Urch, B.; Vincent, R.; Rajagopalan, S.; Silverman, F. Inhalation of fine particulate air pollution and ozone causes acute arterial vasoconstriction in healthy adults. Circulation 2002, 105, 1534-1536.

2. Simkhovich, B.Z.; Kleinman, M.T.; Kloner, R.A. Air pollution and cardiovascular injury epidemiology, toxicology, and mechanisms. J. Am. Coll. Cardiol. 2008, 52, 719-726.

3. Delfino, R.J.; Zeiger, R.S.; Seltzer, J.M.; Street, D.H. Symptoms in pediatric asthmatics and air pollution: differences in effects by symptom severity, anti-inflammatory medication use and particulate averaging time. Environ. Health Perspect. 1998, 106, 751-761.

4. Von Klot, S.; Wölke, G.; Tuch, T.; Heinrich, J.; Dockery, D.W.; Schwartz, J.; Kreylingz, W.G.; Wichmann, H.E.; Peters, A. Increased asthma medication use in association with ambient fine and ultrafine particles. Eur. Respir. J. 2002, 20, 691-702.

5. Dominici, F.; Peng, R.D.; Bell, M.L.; Pham, L.; McDermott, A.; Zeger, S.L.; Samet, J.M. Fine particulate air pollution and hospital admission for cardiovascular and respiratory diseases. J. Am. Med. Assoc. 2006, 295, 1127-1134.

6. International Agency for Research on Cancer. Outdoor Air Pollution: A Leading Environmental Cause of Cancer Deaths. Available online: http://www.iarc.fr/en/media-centre/iarcnews/pdf/pr221_E.pdf (17 October 2013).

7. Loomis, D.; Grosse, Y.; Lauby-Secretan, B.; El Ghissassi, F.; Bouvard, V.; Benbrahim-Tallaa, L.; Guha, N.; Baan, R.; Mattock, H.; Straif, K. The carcinogenicity of outdoor air pollution. Lancet Oncol. 2013, 14, 1262-1263. 
8. Hamra, G.B.; Guha, N.; Cohen, A.; Laden, F.; Raaschou-Nielsen, O.; Samet, J.M.; Vineis, P.; Forastiere, F.; Saldiva, P.; Yorifuji, T.; Loomis, D. Outdoor particulate matter exposure and lung cancer: a systematic review and meta-analysis. Environ. Health Perspect. 2014, 122, 906-911.

9. Jantunen, M.J.; Hänninen, O.; Katsouyanni, K.; Knöppel, H.; Künzli, N.; Lebret, E.; Maroni, M.; Saarela, K.; Srám, R.; Zmirou, D. Air pollution exposure in European cities: The "EXPOLIS" study. J. Expo. Anal. Environ. Epidemiol. 1999, 8, 495-518.

10. Schweizer, C.; Edwards, R.D.; Bayer-Oglesby, L.; Gauderman, W.J.; Ilacqua, V.; Jantunen, M.J.; Laie, H.K.; Nieuwenhuijsen, M.; Künzli, N. Indoor time-microenvironment-activity patterns in seven regions of Europe. J. Expo. Sci.Environ. Epidemiol. 2007, 17, 170-181.

11. International Agency for Research on Cancer (IARC) Working Group on the Evaluation of Carcinogenic Risks to Humans. Some Non-heterocyclic Polycyclic Aromatic Hydrocarbons and Some Related Exposures; IARC: Lyon, France, 2010.

12. Anderson, K.E.; Kadlubar, F.F.; Kulldorff, M.; Harnack, L.; Gross, M.; Lang, N.P.; Barber, C.; Rothman, N.; Sinha, R. Dietary intake of heterocyclic amines and benzo(a)pyrene: Associations with pancreatic cancer. Cancer Epidemiol. Biomark. Prev. 2005, 14, 2261-2265.

13. Butler, L.M.; Sinha, R.; Millikan, R.C.; Martin, C.F.; Newman, B.; Gammon, M.D.; Ammerman, A.S.; Sandler, R.S. Heterocyclic amines, meat intake, and association with colon cancer in a population-based study. Am. J. Epidemiol. 2003, 157, 434-445.

14. Lang, N.P.; Butler, M.A.; Massengill, J.; Lawson, M.; Stotts, R.C.; Hauer-Jensen, M.; Kadlubar, F.F. Rapid metabolic phenotypes for acetyltransferase and cytochrome P4501A2 and putative exposure to food-borne heterocyclic amines increase the risk for colorectal cancer or polyps. Cancer Epidemiol. Biomark. Prev. 1994, 3, 675-682.

15. International Agency for Research on Cancer (IARC) Working Group on the Evaluation of Carcinogenic Risks to Humans, and World Health Organization. Re-Evaluation of Some Organic Chemicals, Hydrazine and Hydrogen Peroxide; IARC: Lyon, France, 1999.

16. International Agency for Research on Cancer (IARC) Working Group on the Evaluation of Carcinogenic Risks to Humans. Formaldehyde, 2-Butoxyethanol and 1-tert-Butoxypropan-2-ol; IARC: Lyon, France, 2006; Volume 88.

17. International Agency for Research on Cancer (IARC) Working Group on the Evaluation of Carcinogenic Risks to Humans. Household Use of Solid Fuels and High-Temperature Frying; IARC: Lyon, France, 2006.

18. Donaldson, K.; Stone, V.; Seaton, A.; MacNee, W. Ambient particle inhalation and the cardiovascular system: potential mechanisms. Environ. Health Perspect. 2001, 109, 523-527.

19. Oberdörster, G.; Oberdörster, E.; Oberdörster, J. Nanotoxicology: An emerging discipline evolving from studies of ultrafine particles. Environ. Health Perspect. 2005, 113, 823-840.

20. Avino, P.; Casciardi, S.; Fanizza, C.; Manigrasso, M. Deep investigation of ultrafine particles in urban air. Aerosol Air Qual. Res. 2011, 13, 654-663.

21. Avino, P.; Lopez, F.; Manigrasso, M. Regional deposition in human respiratory system of submicrometer aerosol determined at $1 \mathrm{~Hz}$ frequency. Aerosol Air Qual. Res. 2013, 13, 1702-1711.

22. Parkash, O. Lung cancer. A statistical study based on autopsy data from 1928 to 1972. Respiration 1977, 34, 295-304. 
23. Hornberg, C.; Maciuleviciute, L.; Seemayer, N.H. Sister chromatid exchanges in rodent tracheal epithelium exposed in vitro to environmental pollutants. Toxicol. Lett. 1996, 88, 45-53.

24. Hornberg, C.; Maciuleviciute, L.; Seemayer, N.H.; Kainka, E. Induction of sister chromatid exchanges (SCE) in human tracheal epithelial cells by the fractions PM10 and PM2.5 of airborne particulates. Toxicol. Lett. 1998, 96-97, 215-220.

25. Ji, W.; Zhao, B. Estimating mortality derived from indoor exposure to particles of outdoor origin. PLoS ONE 2015, 10, e0124238.

26. Knibbs, L.D.; Congrong H.; Duchaine, C.; Morawska, L. Vacuum cleaner emissions as a source of indoor exposure to airborne particles and bacteria. Environ. Sci. Technol. 2012, 46, 534-542.

27. Veillette, M.; Knibbs, LD.; Pelletier, A.; Charlebois, R.; Lecours, P.B.; Congrong, H.; Lidia Morawska, L.; Duchaine, C. Microbial contents of vacuum cleaner bag dust and emitted bioaerosols and their implications for human exposure indoors. Appl. Environ. Microbiol. 2013, 79, 6331-6336.

28. Szymczak, W.; Menzel, N.; Keck, L. Emission of ultrafine copper particles by universal motors controlled by phase angle modulation. J. Aerosol Sci. 2007, 38, 520-531.

29. Wagner, A.Y.; Livbjerg, H.; Kristensen, P.G.; Glarborg, P. Particle emissions from domestic gas cookers. Combust. Sci. Technol. 2010, 182, 1511-1527.

30. Manigrasso, M.; Stabile, L.; Avino, P.; Buonanno, G. Influence of measurement frequency on the evaluation of short-term dose of sub-micrometric particles during indoor and outdoor generation events. Atmos. Environ. 2013, 67, 130-142.

31. He, C.; Morawska, L.; Hitchins, J.; Gilbert, D. Contribution from indoor sources to particle number and mass concentrations in residential houses. Atmos. Environ. 2004, 38, 3405-3415.

32. Wallace, L. Indoor sources of ultrafine and accumulation mode particles: size distributions, size-resolved concentrations, and source strengths. Aerosol Sci. Technol. 2006, 40, 348-360.

33. Hussein, T.; Glytsos, T.; Ondráček, J.; Dohányosová, P.; Ždí'mal, V.; Hämeri, K.; Lazaridis, M.; Smoläk, J.; Kulmala, M. Particle size characterization and emission rates during indoor activities in a house. Atmos. Environ.2006, 40, 4285-4307.

34. Afshari, A.; Matson, U.; Ekberg, L.E. Characterization of indoor sources of fine and ultrafine particles: a study conducted in a full-scale chamber. Indoor Air 2005, 15, 141-150.

35. Hussein, T.; Hämeri, K.; Heikkinen, M.S.A.; Kulmala, M. Indoor and outdoor particle size characterization at a family house in Espoo-Finland. Atmos. Environ. 2005, 39, 3697-3709.

36. Morawska, L.; He, C.; Hitchins, J.; Mengersen, K.; Gilbert, D. Characteristics of particle number and mass concentrations in residential houses in Brisbane, Australia. Atmos. Environ. 2003, 37, 4195-4203.

37. Dennekamp, M.; Howarth, S.; Dick, C.A.J.; Cherrie, J.W.; Donaldson, K.; Seaton, A. Ultrafine particles and nitrogen oxides generated by gas and electric cooking. Occup. Environ. Med. 2001, 58, 511-516.

38. Abt, E.; Suh, H.H.; Allen, G.; Koutrakis, P. Characterization of indoor particle sources: a study conducted in the0metropolitan Boston area. Environ. Health Perspect. 2000, 108, 35-40.

39. Siegmann, K.; Sattler, K. Aerosol from hot cooking oil, a possible health hazard. J. Aerosol Sci. 1996, 27, 493-494. 
40. Wallace, L.; Wang, F.; Howard-Reed, C.; Persily, A. Contribution of gas and electric stoves to residential ultrafine particle concentrations between 2 and $64 \mathrm{~nm}$ : Size distributions and emission and coagulation rates. Environ. Sci. Technol. 2008, 42, 8641-8647.

41. Wallace, L.A.; Emmerich, S.J.; Howard-Reed, C. Source strengths of ultrafine and fine particles due to cooking with a gas stove. Environ. Sci. Technol. 2004, 38, 2304-2311.

42. Rim, D.; Green, M.; Wallace, L.; Persily, A.; Choi, J.I. Evolution of ultrafine particle size distributions following indoor episodic releases: relative importance of coagulation, deposition and ventilation. Aerosol Sci. Technol. 2012, 46, 494-503.

43. Yeh, H.C.; Schum, G.M. Models of human lung airways and their application to inhaled particle deposition. Bull. Math. Biol. 1980, 42, 461-480.

44. Manigrasso, M.; Avino, P. Fast evolution of urban ultrafine particles: Implications for deposition doses in the human respiratory system. Atmos. Environ. 2012, 51, 116-123.

45. Buonanno, G.; Giovinco, G.; Morawska, L.; Stabile, L. Tracheobronchial and alveolar dose of submicrometer particles for different population age groups in Italy. Atmos. Environ. 2011, 45, 6216-6224.

46. Morawska, L.; Afshari, L.; Bae, G.N.; Buonanno, G.; Chao, C.Y.H.; Hänninen, O.; Hofmann, W.; Isaxon, C.; Jayaratne, E.R.; Pasanen, P.; et al. Indoor aerosols: From personal exposure to risk assessment. Indoor Air 2013, 23, 462-487.

47. TSI Particle Technology. Available online: http://www.tsi.com/uploadedFiles/Product_Information /Literature/Catalogs/Particle_Catalog_Web.pdf (accessed on 15 July 2015).

48. Manigrasso, M.; Avino, P.; Fanizza C. Ultrafine particles in the urban area of Rome. Fresenius Environ. Bull. 2009, 18, 1341-1347.

49. Stabile, L.; Buonanno, G.; Avino, P.; Fuoco, F.C. Dimensional and chemical characterization of airborne particles in schools: respiratory effects in children. Aerosol Air Qual.Res. 2013, 13, 887-900.

50. Jeong, C.H.; Greg, J.; Evans, G.J. Inter-comparison of a fast mobility particle sizer and a scanning mobility particle sizer incorporating an ultrafine water-based condensation particle counter. Aerosol Sci. Technol. 2009, 43, 364-373.

51. Laussmann, D.; Helm, D. Air change measurements using tracer gases: Methods and results. Significance of air change for indoor air quality. In Chemistry, Emission Control, Radioactive Pollution and Indoor Air Quality; Mazzeo M., Ed.; InTech: Rijeka, Croatia, 2011; pp. 365-406.

52. Anjilvel, S.; Asgharian, B.A. Multiple-path model of particle deposition in the rat lung. Fundam. Appl. Toxicol. 1995, 28, 41-50.

53. Price, O.T.; Asgharian, B.; Miller, F.J.; Cassee, F.R.; de Winter-Sorkina, R. Multiple Path Particle Dosimetry Model (MPPD v. 1.0): A Model for Human and Rat Airway Particle Dosimetry. Available online: http://www.ara.com/products/mppd.htm (accessed on 16 June 2015).

54. Manigrasso, M.; Buonanno, G.; Fuoco, F.C.; Stabile, L.; Avino, P. Aerosol deposition doses in the human respiratory tree of electronic cigarette smokers. Environ. Pollut. 2015, 196, 257-267.

55. Manigrasso, M.; Buonanno, G.; Stabile, L.; Morawska, L.; Avino, P. Particle doses in the pulmonary lobes of electronic and conventional cigarette users. Environ. Pollut. 2015, 202, 24-31. 
56. Avino, P.; Manigrasso, M.; Pandolfi, P.; Tornese, C.; Settimi, D.; Paolucci, N. Submicron particles during macro-and micro-weldings procedures in industrial indoor environments and health implications for welding operators. Metals 2015, 5, 1045-1060.

57. International Commission on Radiological Protection. Human Respiratory Tract Model for Radiological Protection. Available online: http://www.icrp.org/publication.asp?id=ICRP\%20 Publication\%2066 (accessed on 29 July 2015).

58. Asgharian, B.; Hofmann, W.; Bergmann, R. Particle deposition in a multiple-path model of the human lung. Aerosol Sci. Technol. 2001, 34, 332-339.

(C) 2015 by the authors; licensee MDPI, Basel, Switzerland. This article is an open access article distributed under the terms and conditions of the Creative Commons Attribution license (http://creativecommons.org/licenses/by/4.0/). 